\title{
Qualitative Research to Assess Interest in Public Transportation for Work Commute
}

\author{
Kerstin Carr, University of Regensburg
}

\begin{abstract}
Given the need for reducing single occupancy vehicle commutes, this article presents a case study of employer-based research. Using conjoint analysis as a qualitative research method, factors that potentially influence people's choices to drive alone to work were studied at a major company in Columbus, Ohio. Such factors included reasons for driving alone, satisfaction with commute, perceptions toward transportation modes, importance of transportation attributes, and likelihood to switch if certain Transportation Demand Management measures were implemented. Target groups were formed by using simple regression and cluster analysis of a stated-ranking question regarding transportation attributes.
\end{abstract}

\section{Introduction}

Increased mobility produced by low-density development, rising affluence, and the relative affordability of owning and operating automobiles is clearly valued by people, especially in the United States. Beyond mobility, however, increased automobile use arguably produces a number of negative outcomes, among them are more time spent in traffic congestion; air, water and noise pollution; energy consumption; urban sprawl; and traffic accidents. 
Academic researchers, policy-makers, and practitioners are keenly interested in identifying means of effecting modal shifts among commuters, if not reducing total distance travelled. Among the methods that have been attempted are restrictive policies, such as increasing parking fees and implementing road tolls, or incentive policies, such as offering reduced bus passes. Most of these have proven to be only marginally effective and still do not produce the desired outcomes (Meyer 1999; Baldassare et al. 1998). Therefore, some empirical studies conclude that people are resistant to changing their travel mode (Curtis and Headicar 1997; Moeller and Thoegersen 2003; Bamberg et al. 2003). However, many of these existing approaches to exploring commuting behavior, including the extent to which it occurs and the spatial relationships between home and work locations, are not comprehensive enough measures. To further examine these questions, disaggregate data and qualitative research methods are helpful.

To identify some of the factors that influence people's travel decisions and prevent commuters from using alternative modes of transportation, the presented research applied an in-depth employee survey using conjoint analysis elements. As with qualitative research in general, the research usually does not provide representative data. For the purpose of demonstration, however, the results were used to define target groups for marketing public transportation and to determine the type of actions that would increase an employee's likelihood to switch.

This article presents a case study analyzing the travel behavior of employees of a major company in downtown Columbus, Ohio. Working with private employers allows the researcher to gain easy access to employee information, such as housing distribution and working hours, and to the company's internal and external environment, which provides further explanation of travel behavior. In addition, employers will be more likely to support such research if the study results include concrete recommendations for the site. Further, others have found that employers tend to have a significant impact on reducing commute automobile travel when being actively involved (Winter 2000; Schreffler 2000).

\section{Literature Review}

\section{Qualitative Research}

Social scientists have long been interested in understanding travel behavior, but to this end they have predominately employed quantitative research methods (Golledge and Stimson 1997; Clifton and Handy 2003). Although qualitative tech- 
niques do not yield statistically significant results, they are ideally suited for exploratory research such as identifying influential factors of travel behavior (Golledge and Stimson 1997). Qualitative survey techniques like attitudinal surveys, focus groups, personal interviews, and participant-observation methods provide more detailed answers to current questions and issues regarding transportation and travel behavior. While qualitative methods offer great potential for transportation research, it cannot be argued that they should not be seen as a replacement to quantitative methods, but should be viewed as an extension to assist in explaining psychological and socially influential factors in travel behavior (Clifton and Handy 2003; Goulias 1995; Poulenez-Donovan and Ulberg 2004).

It is well established in the literature that cognitive processes play an important role in determining travel behavior to work (Louviere and Hensher 2001; Axhausen and Sammer 2001). As such, revealed preference, stated preference, discrete choice analysis, and conjoint analysis methods have been used in the field of transportation research to develop predictive choice models. Stated preference experiments are commonly employed for identifying the most important product features or alternatives for travel by providing respondents with different hypothetical scenarios relating to a current behavior such as the work commute (Hunt and Millan 1997; O'Fallon and Hensher 2004). Stated-choice questions demand choosing one of several alternatives or scenarios; stated-preference questions request the evaluation of each alternative by scaling methods; and stated-ranking questions ask the respondents to rank several alternatives by preference.

Conjoint analysis involves the use of designed hypothetical choice scenarios to measure individuals' preferences and predict their choice in new situations. Alternatives are described by their main features, called attributes. Multiple hypothetical alternatives, called product profiles, are generated and presented to respondents who are requested to express their degree of preference for these profiles or choose between these profiles (Backhaus et al. 2000). Conjoint analysis is well suited for travel behavior research because it allows the researcher to estimate the importance a person attaches to different features of a product without direct questioning. Consequently, conjoint analyses can help determine the transportation mode attributes most relevant to the consumer and how variations of the attributes and its levels will influence consumer behavior.

In the present study, conjoint analysis was valuable for identifying the attributes of transportation services that are most important to car drivers and the trade-offs they would be willing to make if certain attribute changes occurred. The research 
was conducted in a qualitative manner. Its main intention was to be comprehensive by surveying a wide variety of possible influential factors, such as spatial, behavioral, psychological, and social ones.

\section{Spatial, Behavioral, Psychological, and Social Theories}

The physical structure of urban environments undeniably influences travel behavior. However, spatial and behavioral theories of travel behavior cannot be treated independently but must be studied together, and urban planning and travel demand management should be complementary processes (Golledge and Stimson 1997; Boarnet and Crane 2001; Holcombe and Staley 2001).

Personal and situational constraints significantly influence travel behavior, and so mode choice depends not only on origin, destination, and sociodemographic characteristics, but also on individual's motives, interests, and intentions. To better identify people's motivations and perceptions regarding transportation and land use, all of the possible influential factors for mode selection should be studied, including personal and external constraints, attitudes toward the different modes of transportation, importance of transportation attributes, and sociodemographics (Anable 2005). The notion that internal constraints on an individual level need to be addressed in addition to the analysis of exogenous forces is vital for developing effective policies (Golledge and Stimson 1997).

Understanding and explaining travel behavior can be further enhanced by relying on psychological theories about attitudes and behavior, and especially theories that offer possible means of predicting behavior (Bordens and Horowitz 2002; Moeller and Thoegersen 2003).

Based on cognitive social psychology theories, attitudes are usually learned through socialization but can be altered through learning processes (Bordens and Horowitz 2002). Others, however, including Moeller and Thoegersen (2003), suggest that travel mode choice is often influenced by habits, and is thus repeated behavior. Repeated behavior helps decrease the volume of cognitive effort necessary for decision making and allows individuals to make decisions with growing automatism. Unfortunately, changing habits is very difficult because it requires more effort to make new decisions, such as time and comfort costs. Also, new decisions are only feasible if sufficient information about alternatives is available.

Huey and Everett (1996) use the "concept of reinforcement delay" to explain resistance to modal change. They argue that the benefits of using alternative modes of transportation, in particular public transit, such as saving gas, decreasing pol- 
lution, and reducing traffic, are important assets. However, the public transit user does not immediately recognize those "rewards." Within their research, Huey and Everett (1996) demonstrate the lack of immediate reinforcement for public transportation systems and the need to create awareness for the "punishers" of private vehicles, such as air pollution, traffic congestion, and higher transportation costs.

Concluding from the above-mentioned theories and empirical findings, it is evident that spatial and behavioral analysis should be undertaken together to successfully influence travel behavior. Psychological studies have revealed that it is important to know about internal constraints and attitudes to understand the decision process for mode choice. In addition, information regarding people's attitudes and the importance they place on attributes of transportation services is needed to help in marketing alternatives successfully.

With these theories and methodologies in mind, an employer-based case study performed in Columbus, Ohio, using qualitative research is described below.

\section{Case Study}

\section{Study Area: Columbus, Ohio}

With more than 1.5 million residents in 2005, the Columbus metropolitan statistical area (MSA) is the 31st most populated MSA in the United States. Since 1990, Columbus' population has grown 12.4 percent, and the Mid-Ohio Regional Planning Commission (MORPC) projects population growth to continue at the same rate until 2010. By 2030 the population is forecasted to increase by 36 percent (MORPC 2004). Employment growth in Central Ohio increased 18 percent between 1990 and 2000, adding more than 120,000 jobs to the region. Vehicle Miles Traveled (VMT) in Columbus has far surpassed population growth, rising 31 percent between 1990 and 2000.

As with many midwestern cities, the vitality of Columbus' downtown has declined in recent decades; this change is marked by the loss of large shopping centers and private employers to the surrounding suburbs (MORPC 2004). However, major efforts are being made to preserve and improve the original Central Business District (CBD). Many companies have headquarters in Columbus' $C B D$ where they could take advantage of a highly developed transportation infrastructure and agglomeration of similar firms and support services.

In addition to concerns about increased VMT and suburban sprawl, Franklin County, which encompasses the majority of the city of Columbus, and five sur- 
rounding counties have been recognized as an air quality nonattainment area. To avoid stringent policies regarding emission regulations, it is necessary to implement strategies that will decrease automobile usage in the future and enhance mobility options for employees despite growing traffic volumes. One possibility is to improve the local transit system by increasing both service coverage and frequency.

\section{Study Object: Employees at a Major Downtown Company}

A single major employer in downtown Columbus was selected for this case study. The company employs more than 2,800 workers at its headquarters, which is located in the Columbus CBD and easily accessible by four major interstates or state highways. Its location also offers reasonable access to public transportation; it is within seven blocks of the transit terminal for all bus lines servicing Franklin County and beyond.

However, an efficient highway network and abundant parking potentially deter many employees from choosing alternative modes. The company currently owns two parking garages with combined 2,010 spaces and rents another 532 spaces, offering a total of 2,542 parking sites to their employees for $\$ 40$ or $\$ 60$ per month. The ratio of 1.1 employees per parking space is high for a dense downtown area.

Although the transportation and urban infrastructure clearly impede the popular use of public transportation, transit still has its place in Columbus and can, when marketed and serviced correctly, obtain a large ridership. Some of the strategies needed to make transit use more attractive are discussed as part of the research results.

\section{Methodology}

The objective of this case study is to identify the presence and importance of latent factors in travel behavior decision making, such as attitudes and perceptions about alternative modes, the work commute and travel costs, and to define different target groups. Therefore, a survey called the "Work Commute Satisfaction Survey" (subsequently referred to as WCSS) was conducted in November 2004. The survey was designed only for current single occupancy vehicle (SOV) users. A total of 60 employees were selected based on their gender, working hours, and residential location. Fifty-two of these employees participated, representing a high response rate of 89 percent. To facilitate participation, the employer provided free lunch on the company's executive floor upon completion of the survey.

The survey contained 53 questions and took approximately 40 minutes to complete. Questions were structured into five different substantive components. Question 
structures included multiple-choice and conjoint analysis elements consisting of ranking, Likert scaling, and a stated-ranking question. The questions were all utilized to gain detailed knowledge about factors that lead SOV commuters to not choose alternative modes, and can be summarized into the following five subject areas:

- Work and Home, including multiple-choice questions such as housing location and choice, employer choice, working hours, or routes to work.

- Commute Travel, including multiple choice, scaling and ranking questions regarding commute to work, reasons for choosing the car, satisfaction with work commute, trip-chaining, possible improvements for route to work, ranking of attributes for transportation services, and personality traits.

- Opinion, including a series of attitudinal questions toward all modes of transportation regarding the employee's (dis)agreement with given statements, ranking of transportation modes by preference, as well as likelihood to switch to alternative modes if certain measures were implemented.

- Suppose ..., including a scenario of transportation characteristics on plan cards for the respondent to rank by preference.

- About You, including multiple-choice questions regarding sociodemographic and socioeconomic aspects of each individual.

The stated-ranking question was conducted by providing the respondents with plan cards that offered 9 out of 27 possible randomly chosen scenarios of commute travel (see Table 1). Each scenario contained one out of three possible choices per attribute. By asking respondents to trade off between scenarios, conjoint analysis is useful for determining the optimal features for a transportation service, in the opinion of the respondent, by estimating the weight people place on various factors that underlie their decisions.

The results were analyzed using the statistical program SPSS as well as a geographical information system to visualize respondents' home locations and estimate transit potential by residency.

In addition to the qualitative survey, an Intranet survey was conducted in May 2005 with all 2,811 employees at the company's downtown headquarters. The objective was to determine the current modal split as well as to provide the employer with more representative data and information about the type of measures that would increase employees' likelihood to switch to alternative modes. For this study, however, focus shall be placed on the analysis of the qualitative survey as the following section describes. 


\section{Table 1. Description of Attribute Cards}

\begin{tabular}{|c|c|c|}
\hline $\begin{array}{l}\text { A } \\
\text { You can leave home or work } \\
\text { whenever you want. } \\
\text { You pay } 30 \% \text { more versus } \\
\text { your current commute. } \\
\text { Your travel time stays the } \\
\text { same. }\end{array}$ & $\begin{array}{l}\text { B } \\
\text { There are only a limited } \\
\text { number of departure times } \\
\text { you can choose from. } \\
\text { Your travel costs stay the } \\
\text { same. } \\
\text { Your travel time stays the } \\
\text { same. }\end{array}$ & $\begin{array}{l}\text { C } \\
\text { There are many departure } \\
\text { times you can choose from. } \\
\text { You save } 30 \% \text { versus your } \\
\text { current commute. } \\
\text { Your travel time stays the } \\
\text { same. }\end{array}$ \\
\hline $\begin{array}{l}\text { D } \\
\text { There are only a limited } \\
\text { number of departure times } \\
\text { you can choose from. } \\
\text { You pay } 30 \% \text { more versus } \\
\text { your current commute. } \\
\text { Your travel time takes } 15 \\
\text { minutes less than now. }\end{array}$ & $\begin{array}{l}\text { E } \\
\text { You can leave home or work } \\
\text { whenever you want. } \\
\text { You save } 30 \% \text { versus your } \\
\text { current commute. } \\
\text { Your travel time takes } 15 \\
\text { minutes less than now. }\end{array}$ & $\begin{array}{l}\text { F } \\
\text { There are many departure } \\
\text { times you can choose from. } \\
\text { Your travel costs stay the } \\
\text { same. } \\
\text { Your travel time takes } 15 \\
\text { minutes less than now. }\end{array}$ \\
\hline $\begin{array}{l}\text { G } \\
\text { There are many departure } \\
\text { times you can choos from. } \\
\text { You pay } 30 \% \text { more versus } \\
\text { your current commute. } \\
\text { Your travel time takes } 15 \\
\text { minutes more than now. }\end{array}$ & $\begin{array}{l}\text { H } \\
\text { You can leave home or work } \\
\text { whenever you want. } \\
\text { Your travel costs stay the } \\
\text { same. } \\
\text { Your travel time takes } 15 \\
\text { minutes more than now. }\end{array}$ & $\begin{array}{l}\text { I } \\
\text { There are only a limted } \\
\text { number of departure times } \\
\text { you can choose from. } \\
\text { You save } 30 \% \text { versus your } \\
\text { current commute. } \\
\text { Your travel time takes } 15 \\
\text { minutes more than now. }\end{array}$ \\
\hline
\end{tabular}

\section{Results}

\section{Identifying Target Groups through Self-Selection of Attributes}

Often, Transportation Demand Management (TDM) marketing strategies are directed toward specific target groups. Such target groups can either be defined by their travel behavior or their values for transportation attributes.

The WCSS survey produced no significant results for forming target groups by residential area or by sociodemographic variables. Instead, an analysis of the importance of transportation features, such as flexibility, time, and cost, implied that it would be more useful to divide commuters into each one of these groups.

Two WCSS questions were used to either request the participant's ranking of attributes by preference or to demand an orderly scaling of attributes from $5=$ Very important to $1=$ Very unimportant. The ranking order for both questions 
resulted as follows: flexibility, then time, then cost. Time seemed to be the second most important factor in choosing a mode. However, the stated-ranking question provided different results. This task asked participants to rank index cards that described feature characteristics of transportation choices by their preference (see Table 1). Only transportation attribute scenarios and attribute levels were provided to the participants, without referring each scenario to a particular mode. Thus, perceptions about other modes should not have influenced the preference ranking. Time received the lowest relevance when choosing between possible transportation scenarios. The average importance of the three attributes was as follows: flexibility ( 41 percent), cost (36 percent), and time (21 percent).

This discrepancy in results could be explained by the amount of savings (30 percent/15 minutes) described in the plan cards, suggesting that the ranking order of attributes will change depending on the amount of money or time that could be saved. The results also indicate that cost becomes more important when reaching a certain level. Thus, as cost rises, flexibility and time decrease in value. Further research is necessary to help define the threshold that will increase the value of cost savings.

To determine the importance or utility individuals placed on each attribute by their rank choice, a simple regression analysis was performed. In this case, the rankings of each respondent were dummy-effect coded and interpreted as metricscaled dependent variables while the attributes and their parameter values served as the independent variables. Target groups were defined based on the value each member placed on the attribute.

To differentiate between target groups, a cluster analysis was applied by quantitatively comparing multiple characteristics. Thus, respondents were placed into more or less homogeneous groups. The cluster analysis for this research was performed by using the Ward Method and the squared Euclidian distance (Backhaus et al. 2000).

As described earlier, qualitative research will not enumerate statistical frequencies but rather can provide further information about behavioral and influential factors on mode choice. Thus, due to the small sample size, results will only present tendencies of the member's characteristics in each group.

\section{Attribute Groups}

Although all participants state that convenience is the most important transportation attribute for them, not all participants fell into the "flexibility" category 
when analyzing their plan card choices. Instead, nearly half of the participants seemed to be more concerned about costs, while another 10 percent valued time the most. As Table 2 illustrates, members of each attribute group differ based on selected characteristics.

For example, cluster 1 (flexibility) consists of more women. Half of all group members have a bus stop near their home, yet if no car was available, most would want to carpool. Clearly, cost savings is not very important. While many have to pick up their children before or after work, participants in this group demonstrate the highest overall satisfaction with their current commute. Consequently, members of cluster 1 indicate the least overall likelihood to switch to alternative modes. More than 38 percent of the participants state that they are "much more likely" to switch in response to only three scenarios: The implementation of a Guaranteed Ride Home (GRH) program, increased traffic congestion, and the implementation of a light rail system.

Participants in cluster 2 (cost) are primarily employees with a college degree who tend to have a higher interest in public transportation. This group further contains a significantly higher percentage of employees who occassionally use alternative modes. More than 41 percent of the interviewees indicate a higher likelihood to switch to alternative modes of transportation if a GRH program were implemented, gas prices increased, parking search and cost increased, congestion grew worse, or if a light rail were implemented.

In cluster 3 (time), men seem slightly overrepresented. Interviewees in this group are all employees with a college degree and a household income of $\$ 80,000$ or more. While none had a bus stop near their home, this group demonstrates the highest likelihood to switch. The measures that would make over 40 percent of the participants "much more likely" to switch to other modes include the implementation of a GRH program, receiving money for not using a parking space, increased parking search and costs, growing congestion, assistance in arranging car- and vanpools, reserved parking, construction of HOV Lanes, increased bus services, and the implementation of a light rail system. 


\section{Table 2. Characteristics of WCSS Participants per Attribute Cluster}

\begin{tabular}{|c|c|c|c|}
\hline & $\begin{array}{r}\text { Cluster 1: } \\
\text { Flexibility }(N=21)\end{array}$ & $\begin{array}{r}\text { Cluster 2: } \\
\text { Cost }(N=22)\end{array}$ & $\begin{array}{r}\text { Cluster 3: } \\
\text { Time }(N=5)\end{array}$ \\
\hline $\begin{array}{l}\text { Gender } \\
\text { Female } \\
\text { Male }\end{array}$ & $\begin{array}{l}38 \% \\
62 \%\end{array}$ & $\begin{array}{l}14 \% \\
86 \%\end{array}$ & $\begin{array}{l}20 \% \\
80 \%\end{array}$ \\
\hline Primary age group(s) & $46-55(40 \%)$ & $36-45+46-55(64 \%)$ & any \\
\hline Married & $76 \%$ & $90 \%$ & $80 \%$ \\
\hline Highest level of education & $\begin{array}{r}\text { Varies from high } \\
\text { school to } \mathrm{PhD} \text { degree }\end{array}$ & $\begin{array}{r}\text { All have continuing } \\
\text { education }\end{array}$ & $\begin{array}{l}\text { All have at least a } \\
\text { bachelor's degree }\end{array}$ \\
\hline Household income & $\$ 20,001$ to $>\$ 140,000$ & $\$ 40,001$ to $>\$ 140,000$ & $\$ 80,001$ to $>\$ 140,000$ \\
\hline $\begin{array}{l}\text { Availability of bus stop at } \\
\text { home }\end{array}$ & $50 \%$ & $27 \%$ & $0 \%$ \\
\hline $\begin{array}{l}\text { Occasionally use other } \\
\text { modes to work }\end{array}$ & $14 \%$ & $31 \%$ & $0 \%$ \\
\hline $\begin{array}{l}\text { Used alternative modes } \\
\text { before }\end{array}$ & $76 \%$ & $77 \%$ & $40 \%$ \\
\hline $\begin{array}{l}\text { If no car was available } \\
\text { Carpooling } \\
\text { COTA bus }\end{array}$ & $\begin{array}{l}57 \% \\
29 \% \\
\end{array}$ & $\begin{array}{l}32 \% \\
45 \% \\
\end{array}$ & $\begin{array}{l}20 \% \\
20 \% \\
\end{array}$ \\
\hline $\begin{array}{l}\text { Overall satisfaction with } \\
\text { commute (Scale } 1 \text { to } 5 \text {, } \\
\text { with } 5 \text { = Very satisfied) }\end{array}$ & [Range: $3.1-5.0]$ & [Range: $2.8-4.8$ ] & [Range: $2.7-3.2$ \\
\hline Pick up children & $\begin{array}{r}19 \%: \text { daily } \\
14 \%: 1-2 \text { times/week }\end{array}$ & $\begin{array}{r}13 \%: \text { daily } \\
4 \%: 1-2 \text { times/week }\end{array}$ & $0 \%$ \\
\hline $\begin{array}{l}\text { Rank attributes }^{2} \\
\text { Convenience } \\
\text { Cost savings } \\
\text { Time savings } \\
\end{array}$ & $\begin{array}{l}1.7 \\
4.9 \\
3.7 \\
\end{array}$ & $\begin{array}{l}2.2 \\
3.7 \\
4.4\end{array}$ & $\begin{array}{l}1.4 \\
3.4 \\
3.8\end{array}$ \\
\hline $\begin{array}{l}\text { Participants who rank } \\
\text {... as most important: }^{\mathrm{a}} \\
\text { Convenience/flexibility } \\
\text { Cost savings } \\
\text { Time savings }\end{array}$ & $\begin{array}{r}76 \% \\
0 \% \\
9 \%\end{array}$ & $\begin{array}{r}73 \% \\
0 \% \\
5 \%\end{array}$ & $\begin{array}{r}80 \% \\
20 \% \\
0 \%\end{array}$ \\
\hline $\begin{array}{l}\text { Importance of attributes } \\
\text { Convenience } \\
\text { Cost savings } \\
\text { Time savings }\end{array}$ & $\begin{array}{r}100 \% \\
85 \% \\
100 \%\end{array}$ & $\begin{array}{r}100 \% \\
86 \% \\
86 \%\end{array}$ & $\begin{array}{r}100 \% \\
60 \% \\
100 \%\end{array}$ \\
\hline $\begin{array}{l}\text { Attitudes toward different } \\
\text { modes of transportation }^{c}\end{array}$ & $\begin{array}{r}\text { Bus: } 3.4 \\
\text { Car/vanpooling: } 3.5\end{array}$ & $\begin{array}{r}\text { Bus: } 3.5 \\
\text { Car/vanpooling: } 3.8\end{array}$ & $\begin{array}{r}\text { Bus: } 3.3 \\
\text { Car/vanpooling: } 3.5\end{array}$ \\
\hline $\begin{array}{l}\text { Overall likelihood to switch } \\
\text { (1=Not at all likely to } 3=\text { Very likely) }\end{array}$ & 1.58 & 2.02 & 2.13 \\
\hline
\end{tabular}

a. Within the survey question, participants were asked to rank 12 attributes from $1=$ highest rank to 12 = lowest rank (Calculated: SUM Rank numbers divided by SUM Participants).

b. "\%" indicates the combined percentage of participants who claimed that a particular attribute is either "very important" or "somewhat important" (Scale 1 to 5).

c. A list of 60 different attitudinal statements regarding travel behavior and transportation modes was provided to each participant, asking them to rank each one on a scale from 1 to 5 , with $1=$ Strongly disagree to $5=$ Strongly agree. The statements regarding bus usage and carpooling were then summarized and weighted to receive an overall score regarding the participant's attitude toward these modes. Therefore, $5=$ positive versus a $1=$ negative attitude. 


\section{Summary and Recommendations}

The overall study results suggest that flexibility, cost, and time are the most important reasons for choosing a transportation mode. These results are not surprising. However, answers of the stated-ranking question indicate that commuters will trade off transportation attributes if provided with concrete scenarios. For this particular study, results demonstrated that flexibility and time decrease in value when cost reaches a certain level.

Travel demand management strategies can be enhanced by marketing efforts directed toward members of each attribute group, based on their observed transportation characteristics. According to the presented research, it can be assumed that people's sensitivity to transportation attributes significantly influence their likelihood to make certain travel decisions, and that the value they place on travel characteristics cannot be elucidated by only their sociodemographic characteristics.

When forming target groups by using these attributes, it is obvious that TDM concepts which value a particular attribute seem to work best for each group and therefore should be marketed accordingly. For example, cost-sensitive commuters, such as in cluster 2, will react quicker to obvious increases in travel costs, such as parking or gas, while time-sensitive employees, such as in cluster 3, should be provided with personal assistance on carpooling and transit. When implementing any of the TDM strategies, it is important to market the qualities of each measure in such a way that it is compelling to the members of the group it addresses. For example, marketing TDM measures related to cluster 3 should be directed to highpaid male professionals living in the suburbs.

Public transportation, in particular, tends to be the most efficient alternative transportation service for any commuter if applied and marketed correctly. An improved transit service can address each identified target group. Unfortunately, like many transit systems in the United States, the local bus authority is plagued by a lack of adequate funding. Decreased federal and state funding and low farebox revenue, the result of low ridership, promises continued financial troubles for the transit authority. For reasons related to the transit service constraints, two options should go hand in hand:

1. Focusing information and marketing on those transit routes that are most accessible to employees' homes as well as nearest to the company while 
keeping each target group attributes in mind. It often is not enough to just provide the service but to also ensure that the employees know about it.

2. Encouraging public-private partnerships on transportation infrastructure projects, including subsidizing transit in order to increase service frequency and speed. In general, service expansion rather than decreased fares has proven to be a more effective means of increasing ridership (Schimek 1996).

Overall, many fundamental policies which can create a better balance between auto and transit are very important in influencing the analyzed decision process. Such policies include the increase in gas taxes to use toward public transportation, or allowing for more flexible working hours and types (e.g., telecommuting).

\section{Future Research}

Travel behavior is a complex process that promises to remain a rich area for transportation research. The use of qualitative methods and scenario-building tools, such as the conjoint analysis presented here, are examples of the potential for innovative methods in TDM to get a more in-depth understanding of travel choices. Several potential areas of future research related to this study include more investigation of the type of scenarios and the parameter values that are most appropriate as thresholds when commuters change the ranking of attribute values, and to test if the results of this study and the identified clusters are representative of a larger population. Since this research was conducted in a very auto-oriented environment, it would also be interesting to see if similar results are obtained when studying a commuter population in a city with much more transitoriented land use and service coverage.

As indicated in this article, employers play a significant role in achieving commuter modal shift. As such, more research should be conducted to identify successful means of encouraging companies to actively participate in local transportation projects and as a result implement measures that are responsive to their employees' travel needs. Cooperating with surrounding companies could then lead to more effective measures aimed at improving public transportation, biking lanes, and sidewalks.

In addition to only addressing individual companies to get involved in TDM, future research could also include studying the type of impact that multiple employers 
can have on changing basic transportation policies toward more positive ones for transit when cooperating with the city and public transit agency.

\section{Acknowledgments}

The author would like to thank Prof. Dr. Kurt Klein from the University of Regensburg for his invaluable support of the research, and Lynn Robinson for her participation and for providing important resources to the project. A special thanks goes out to Eric Schreffler for his continuous encouragement. The author greatly appreciates the active involvement of the surveyed company in the research project. Thanks also to the anonymous reviewers for their input.

\section{References}

Anable, J. 2005. Complacent car addicts or, aspiring environmentalists? Identifying travel behaviour segments using attitude theory. Transport Policy 12: 65-78.

Axhausen, K., and G. Sammer. 2001. Stated responses. Überlick, Grenzen, Möglickkeiten. Arbeitsbericht Verkehrs- und Raumplanung 73: 1-21.

Backhaus, K., B. Erichson, W. Plinke, and R. Weiber. 2000. Multivariate Analysemethoden. Eine anwendungsorientierte Einführung. Berlin: Springer.

Baldassare, M., S. Ryan, and C. Katz. 1998. Suburban attitudes toward policies aimed at reducing solo driving. Transportation 25: 99-117.

Bamberg, S., D. Rölle, and C. Weber. 2003. Does habitual car use not lead to more resistance to change of travel mode? Transportation 30(3): 97-108.

Boarnet, M., and R. C. Crane. 2001. Travel by design: The influence of urban form on travel. Oxford: Oxford University Press.

Bordens, K., and I. A. Horowitz. 2002. Social psychology. London: Lawrence Erlbaum Associations, Inc.

Clifton, K. J., and S. L. Handy. 2003. Qualitative methods in travel behaviour research. In Stopher, P. and P. Jones, eds., Transport Survey Quality and Innovation. New York: Pergamon: 283-302.

Curtis, C., and P. Headicar. 1997. Targeting travel awareness campaigns. Which individuals are more likely to switch from car to other transport for the journey to work. Transport Policy 4(1): 57-65. 
Golledge, R. G., and R. J. Stimson. 1997. Spatial behavior: a geographical perspective. New York: Guilford Publications, Inc.

Goulias, K. G. 1995. On the role of qualitative methods in travel surveys. In Stopher, P. and P. Jones, eds., Transport Survey Quality and Innovation. Boston: Pergamon: 319-330.

Holcombe, R., and S. R. Staley. 2001. Smarter growth: Market-based strategies for land-use planning in the 21st century. Westport: Greenwood Press.

Huey, J. A., and P. B. Everett. 1996. Immediate benefits: The reason for the car's success and transit's failure. Transportation Research Record 1521: 65-70.

Hunt, J. D., and J. D. P. McMillan. 1997. Stated-preference examination of attitudes toward carpooling to work in Calgary. Transportation Research Record 1598: 8-17.

Louviere, J., and D. A. Hensher. 2001. Combining sources of preference data. In Hensher, D. A., ed., Travel behaviour research. The leading edge. Amsterdam: Elsevier: 125-144.

Meyer, M. D. 1999. Demand management as an element of transportation policy: Using carrots and sticks to influence travel behavior. Transportation Research Part A 33: 575-599.

MORPC-Mid-Ohio Regional Planning Commission. 2004. Regional fact book. Regional growth strategy. Central Ohio. Columbus.

Moeller, B., and J. Thoegersen. 2003. Car-use habits: An obstacle to the use of public transportation? Presented at the TRIP Conference, Hilleroed.

O'Fallon, C., C. Sullivan, and D. A. Hensher. 2004. Constraints affecting mode choices by morning car commuters. Transport Policy 11: 17-29.

Poulenez-Donovan, C., and C. Ulberg. 2004. Seeing the trees and missing the forest: Qualitative versus quantitative research findings in a model transportation demand management program evaluation. Transportation Research Record 1459: 1-6.

Schimek, P. 1996. Automobile and public transit use in the United States and Canada: Comparison of postwar trends. Transportation Research Record 1521: 3-11. 
Schreffler, E. 2000. State of the practice: Mobility management monitoring and the evaluation in the United States. MOST. Mobility Management Strategies for the Next Decades. Work Package 3, D3 Report. Aachen.

Winter, P. L. 2000. Transportation demand management. Transportation Research Board.

\section{About the Author}

KeRSTIN CARR (kcarr@morpc.org) is a senior transportation planner for the Mid-Ohio Regional Planning Commission (MORPC) in Columbus, Ohio, working primarily on transportation safety and ITS short- and long-range planning for the Central Ohio region. She holds a master's degree in geography from the University of Regensburg in Germany with minors in business administration and psychology. The presented research is part of her Ph.D. studies. Prior to her association with MORPC, Mrs. Carr worked as a project leader for Siemens Automotive on employerbased TDM. During her work, she initiated a public-private partnership between neighboring employers, the City, and the transit agency to increase bus service frequency to company sites. Mrs. Carr cochairs the communication committee of the WTS Columbus chapter and is a member of the TRB TDM committee. 